Jan. 7th, 1858. - Has more pain, and there is undue fulness over the region of the liver, though no material enlargement downwards. Leaning on the right side causes pain, and he complains of pain and soreness in the right shoulder and along the inner side of the arm. Ordered the nitro-muriatic acid bath every night. This seemed to do good, especially as regards the functions of the liver, and in diminishing the hectic fever.

On the 26th he complained of formication over the chest and abdomen, and occasional hiccough, and the bath was discontinued.

On the 29 th he was worse; felt much prostration; more pain in the right hypochondrium, increased on moving or coughing, and he had sweated copiously at night.

From this date, through the month of February and greater part of March, he continued, with occasional improvements for a day or two, to get worse; the hepatic symptoms and indications of suppuration becoming more marked, and the constitutional disturbance, in the way of hectic fever, and subsequent perspirations, greater.

March 26th. -The abscess is pointing just above the angle formed by the junction of the cartilages with the osseous portion of the last ribs. The liver extends about an inch and a half below the normal limits. The adhesion of the liver with the parietes is determined by the former not shifting its position with a shifted position of the patient, or with the acts of expiration and inspiration. As the patient was becoming exhausted, it was determined to open the abscess. This was accordingly done with a sharp-pointed bistoury, and about a pint of curdy pus escaped. The abscess continued to discharge, especially under the acts of coughing and deepinspiration, and the severer constitutional and local symptoms were relieved. He continued, however, notwithstanding the free administration of brandy, wine, and beef-tea, to get more prostrated and emaciated, and died on April 5th.

Inspection. - Body emaciated. Liver encroaching on the right half of the chest to the level of the third rib. Right lung compressed, carnified below, cedematous above. At the apex three cicatrices, but no evidence of present tuberculous condition. Left lung healthy. Anterior surface of liver firmly fixed to abdominal parietes for several inches around the external aperture. Weight of liver, six pounds and a half. In the right lobe there was a large abscess, with smaller ones communicating with it. It had burrowed outwards and downwards until it reached below the ribs, then forwards and through the parietes. No appearance of gangrene. A number of smaller abscesses, about the size of a walnut, occupied the right and left lobes, and contained greenish pus. Intervening hepatic structure healthy. The spleen weighed six ounces, and was healthy; right kidney pale and flabby, left healthy; some of the mesenteric glands enlarged. Large intestine dotted over with circular ulcers, with raised indurated borders; a few had irregular congested borders. The mesenteric and portal veins were healthy.

$$
\text { (To be continued.) }
$$

A CASE IN WHICH, AFTER THE REMOVAL OF SEVERAL INCHES OF THE MUSCULOSPIRAL NERVE, THE SENSIBILITY OF THAT PART OF THE SKIN OF THE HAND WHICH IS SUPPLIED BY IT WAS RETAINED.

By WILLIAM S. SAVORY, F.R.S., BURGEON TO ST. BARTHOLOMEW'S HOSPITAL.

J. I__ a , aged thirty-eight, a groom, was brought to me at the hospital by Mr. Goddard, in whose service he has been for many years, with a large tumour in the right arm. It occupied the lower third of the front and outer aspect, the biceps bounding it internally. It was very dense, regularly oval, and measured four inches in length and three in breadth. It was prominent, close under the skin, freely movable, and apparently without any firm connexion to surrounding parts. The tumour itself was not painful, except when rudely handled, but he complained of a tingling sensation passing from the tumour down the forearm to the hand. It had existed for several years, but, growing slowly at first, it had of late increased more rapidly, and now rendered the arm almost useless for work. In the lower third of the forearm, over the outer and back part of the radius, there was a much smaller and softer tumour, irregularly flattened, of which he took no heed because it produced no inconvenience whatever. Another tumour, very similar in shape and consistence to the last, was discovered over the right scapula; and a somewhat soft pedunculated growth, about the shape and size of a small pear, hung from the integument near the occipital crest. Imbedded in the skin over the whole body were numerous small tumours, rarely larger than a pea, of whose existence he did not appear conscious. He was a dark, thick-set man, of singular aspect, and peculiar in manner, rather slow of comprehension, with a remarkable hesitation in his speech. His past health had been good, and no evidence of any further disease could be detected. He was anxious to get relief from the large tumour, but otherwise indifferent.

On the 14th of last December the large tumour was removed. A thin stratum of muscular fibres - part of the brachialis anticus-was spread over its surface. It was readily isolated from all adjacent parts except at its extremities, to which the whole trunk of the musculo-spiral nerve was attached. As the nerve evidently passed into and out of the substance of the tumour, it was divided above and below, about an inch from either end, and then the tumour was at once removed. The cut extremities of the nerve appeared quite healthy. When the tumour was divided by a longitudinal section and examined, it was found to be composed throughout of fibrous tissue, which in the outer half was firm, and presented all the characters, well marked, of a fibrous tumour, but towards the centre was more opaque, softer, and friable, and displayed there, in addition to many imperfectly marked fibres, an abundance of granules and molecules of oil. This portion $0_{4}$ the tumour was evidently in a state of fatty degeneration. When the nerve was traced into the substance of the tumour, its fibrils could be followed for some distance, spreading out in every direction, until at length they were lost amidst the bands and bundles of fibres. The tumour was clearly a neuroma, and had grown in the midst of the fibrils of the musculospiral nerve, unravelling them as it had enlarged. The surfaces of the large wound were brought together and lightly supported by a bandage. All went on fairly well after the operation. For forty-eight hours there was some fever, but on the third day he was free from any constitutional disturbance. At first, too, the arm, forearm, and hand were much swollen, and the integuments puffy, but in a day or two the limb resumed its natural aspect. The wound suppurated, but not freely, and so gradually closed in.

From the time of the operation the muscles of the back of the forearm were paralysed, and the hand dropped forward from the wrist. But, when testing the sensibility of that portion of the skin of the hand which is supplied by branches of the radial nerve, we were not a little astonished to find that it was but slightly impaired. When the skin upon the outer part of the back of the hand, or over the back of the thumb and forefinger, was lightly pricked, the man cried out sharply. He could distinguish in the same region two points of contact when they were not more than an inch apart, both in the long and transverse axes of the hand; when they were closer than this on any part of the back of either hand or forearm, he confused them; and, indeed, in comparing the sensibility of this region with that of the inner portion of the back of the hand, and two inner fingers, or with the corresponding part of the opposite hand, no very striking difference could be detected. All portions, too, of the back and sides of the middle finger appeared equally sensitive. He could distinguish also between the contact of hot and cold bodies in this region as well as in other parts. He always remarked the distinction between the touch of a cold steel sound and one that had been previously dipped in hot water. When desired to experiment upon himself by touching, scratching, or pricking the different parts, he repeatedly declared either that he could perceive no difference of sensibility, or that the radial portion of the dorsum of the hand was rather more sensitive than the other half. These observations were carefully repeated in various ways, day after day, with a uniform result ; indeed, the man at last got tired of them, concluding, no doubt, that the existence of acute sensibility had been abundantly proved. It need hardly be said that in many of these experiments the man was blindfolded, and otherwise prevented from forming any idea of what we did except through the sense of touch.

Now, what is the interpretation of this remarkable fact? All anatomists will agree that, so far as ordinary dissection goes, the skin on the outer half or thereabout of the back of the hand, and of the back of the thumb, forefinger, and outer 
portion of the back of the middle finger, is supplied only by branches of the radial nerve; and when any variation is noticed in the distribution of this nerve to the back of the hand, it is almost always that it supplies more than the usual proportion of integument, going on sometimes to the ring finger. I cannot doubt therefore that in this instance the parts in question were supplied in the usual way-only through the branches of the radial nerve. But then how could these parts retain sensibility after the removal of some inches of the nerve-trunk? I can only account for it thus :- We know that in the forearm, just above the wrist, some small branches of the external cutaneous nerve communicate with the radial, and it may be that at this junction the radial receives filaments from the external cutaneous, which so pass down to be distributed, with the filaments of the radial, even to the skin of the hand. This seems to me to be the most probable view of the matter-indeed, the only reasonable one. There should assuredly be more difficulty in conceiving such a transference of the filaments of the ulnar and radial on the back of the hand. The arrangement of the small branches so near their distribution would hardly admit of this. But if this explanation be the true one, it suggests a much larger question. Are nerves so isolated in their distribution as they are now believed to be? Is not the purpose of the communication between different nerves in their course more extensive and complete than has been hitherto recognised? The question is one which appears to be beyond the reach of any ordinary dissection, and perhaps it will be best answered hereafter by observation and experiment in cases like the present one.

Let me add that this case is not an isolated one. In THE LANCET of the $30 \mathrm{th}$ of last November there is a notice of a case which was then in the wards of Professor Richet at La Pitié, exciting much interest and speculation. In the patient, young woman of twenty-four, the median nerve "was completely cut through" a short distance above the wrist. "Yet sensibility of the lower end of the nerve was unimpaired. The patient screamed with pain as M. Richet excised a minute portion of it for microscopical examination. All the parts to which the median nerve is distributed had likewise retained their sensibility." But "the muscular contractility of the parts supplied by the nerve was completely lost, and the application of electricity failed to elicit any contraction." See Gazette des Hópitaux, 1867, Nos. 131 and 134, for additional details and a discussion of the chief facts observed in this re markable instance.

\section{MALARIA FEVER IN CORSICA.}

BY J. HENRY BENNET, M.D.

I HAVE recently returned from a third exploration of Corsica, undertaken with a view to ascertain the conditions under which malarious fever is generated in that lovely island. I wished particularly to learn whether its existence in summer may be considered a drawback to Corsica's being regarded one of the winter sanitaria of the Mediterranean. Having been the one to discover Ajaccio medically, as it were, in 1862, and finding that the efforts I have since incessantly made to direct attention to its special advantages are at last about to be crowned with success, I thought it incumbent on me to study this malaria question, that $I$ might not prove a false guide and prophet.

I landed at Ajaccio on the 22nd of April, and found every thing in a prosperous and promising condition. Two medical friends, who had passed a couple of winters with me at Mentone-Dr. Bierman, a German physician, and Dr. Ribton, of Dublin-have definitively settled there, and have placed themselves at the head of the movement. A considerable number of German and British invalids have passed the latter part of the past winter under the care of these gentlemen at Ajaccio, and all, I believe, have been much pleased with their experience of the new health colony. A sufficient amount of money has been subscribed to build a large and commodious hotel, and in the meanwhile every effort is being made to improve the existing accommodation for next winter. These medical gentlemen will take private patients, and there will be at least one good boarding-house. For further details respecting this new health colony I must refer to my work entitled "Winter in the South of Europe." I would only add, as it has been extensively reported that I mean to settle there myself, that I have no such intention. I have no other interest in A jaccio than the philanthropic wish to be of use to the tribe of invalids whom I warn off from the large southern towns, by finding ont for them, in addition to Mentone and the Genoese Riviera, a new and interesting locality, with an island climate-in some forms of disease a decided advantage.

On leaving Ajaccio I travelled south to Sartene and Bonifacio, and then ascended the Oriental coast up to Bastia and Cap Pino, examining specially the mouths of the rivers, and conversing with all the native medical men I met. I also paid a visit to the penitentiary of Salabianda on the eastern coast, where 1000 convicts are employed in draining most pestilential marshes, and respecting which $I$ have some interesting details to give.

The following are the results at which $I$ arrived. Wherever a river or torrent descends from the mountains or valleys, and empties itself into the sea, there is malaria, or intermittent fever, in the plains which it waters, from the sea-level to an altitude varying from 100 to 200 feet. This I ascertained with the barometer. On ascending these valleys, when the barometer indicated an elevation of from 150 to 200 feet $\mathrm{I}$ was all but invariably told, "Now we are safe; people can live here all the year round." In the more malarious regions of these plains I generally found that we were only a few feet above the sea-level, and that the country was nearly flat. The fever sets in towards the latter end of June, increases in intensity until October, and disappears towards the end of October, as the nights become colder. It is often very severe, and assumes occasionally the pernicious form. It complicates nearly all other diseases that occur whilst it reigns. On the eastern coast, where there are a series of marshes and ponds through which the rivers empty themselves into the sea, the malarial fever is more severe and more fatal than elsewhere.

There are a few villages and isolated houses in these mala rious plains, but they are only inhabited during the cool months of the year. By the beginning or middle of July the harvest is over, and then the entire population abandon their homes and go to the mountains behind, there to occupy other habitations at an altitude of several thousand feet, during the hot months. Well-to-do people leave at the beginning of June, to return at the end of October. The working class leave when the harvest is over in July, and return early in October to till the ground.

Intermittent fever exists not only in Corsica, but in all the Mediterranean islands, and on the mainland, under the same conditions, wherever a river runs into the sea. It appears to me that the extreme prevalence of intermittent on the Mediterranean shores, at the outlets of rivers, in a temperate climate, is in a great measure owing to the sea being all but tideless. When storms come, the sand and shingle are thrown up in great masses at the mouth of the rivers. There is no tidal scour as in the Atlantic, so that the waters of the river are pent up, flow back, and swamp all the low lands, saturating them with moisture. As dead and decaying vegetable matter is not purified by the action of winter frosts, as in northern countries, the advent of the powerful summer sun produces that state of soil which gives rise to aguish fevers. One thing is certain, that it requires no marsh or pond to produce malaria. Some of the most pestilential plains I saw - plains where human beings cannot live in summer-were as healthy, as innocent-looking in April and May as the banks of the Trent or the Thames. It really seems quite sufficient to produce aguish fever in a subtropical country that the land should have been saturated with water, either from rain or overflow, in winter, that there should not be a good fall for drainage, and that the July heat should be reached. The natives of these countries know this, and act accordingly; but northerners do not, and are often difficult to convince, to their own destruction. They cannot believe that a smiling cornfield by the side of a pure running stream, such as they have fished in and bathed in day after day in their youth, during sultry August weather at home, can possibly be in these countries pestilential-a place to fly from as soon as spring is over. They pooh. pooh such reports. They think the natives faint-hearted lazy cravens, and go about their work as at home, to sicken and die in a year or two. I heard several such tales in Corsica, but the most remarkable is the history of the Salabianda penitentiary, above alluded to. It is an agricultural colony of convicts, founded by the French Government five years ago, in order to drain and reclaim some of the ponds and swamps of the Oriental coast. Unfortunately the Government gave the appointment of director to a clever energetic officer, but a northerner, who knew nothing of Corsica or its fever. $\mathrm{He}$ thought all he heard fudge; that the fever was the result of the men working in the heat of the day and being badly fed. So he 